\title{
Sobre a China e o "socialismo de mercado" como uma nova formação econômico-social
}

On China and the "Market Socialism" as new socio-economic formation

\author{
Elias Jabbour (1) \\ Alexis Dantas (1) \\ (1) Universidade do Estado do Rio de Janeiro (UERJ)
}

\begin{abstract}
The aim of this paper is to demonstrate that the growth of the state sector in the Chinese economy, accelerating since 2009, opens conditions to conclude that the Chinese model is something that is distancing itself historically from a typical model of state capitalism and is even further from being a liberal capitalism. Faced with a range of evidence, we affirm that the market socialism in China can already be classified as a "New Socio-Economic Formation" (NSEF) that has its main attribute in complexity, since it implies that it is a formation marked by the coexistence of different modes of production. Since it is not social formation at the height of its development, the market socialism must be treated as a phenomenon governed by combinations of different modes and relations of production. Classifying and exposing the laws governing the development of socialist market economy will be the aim of the analysis in this work.
\end{abstract}

\section{Keywords}

China, socialist market economy, complex MP, development, marxist category of socioeconomic formation.

JEL Codes O1, O2, P2.

\section{Resumo}

O objetivo deste artigo é demonstrar que o crescimento do setor estatal na economia chinesa acelerado desde 2009, abre condições para a possibilidade de o "modelo chinês" se tratar de algo que vai se distanciando - historicamente de um modelo típico de "capitalismo de Estado", e mais longe ainda de ser um "capitalismo liberal". Diante de uma gama de evidências afirmamos que o "socialismo de mercado" já pode ser classificado como uma nova formação econômico-social (NFES) que tem na complexidade seu principal atributo, pois implica tratar-se de uma formação marcada pela convivência de diferentes modos de produção. Por não se tratar de uma formação social no auge de seu desenvolvimento o "socialismo de mercado" deve ser abordado como um fenômeno regido por combinações entre diferentes modos e relações de produção. Classificar e expor as lógicas que regem o desenvolvimento do "socialismo de mercado" será objeto de análise neste trabalho.

\section{Palavras-chave}

China, socialismo de mercado, modo de produção complexo, desenvolvimento, categoria marxista de formação econômico-social.

Códigos JEL O1, O2, P2. 


\section{Introdução}

O desenvolvimento chinês é, talvez, o fenômeno mais importante do mundo presente. Seu crescimento médio do Produto Interno Bruto (PIB) nos últimos 35 anos foi de $9,5 \%$ a.a., ao mesmo tempo que a renda per capita no período passou de US\$ 250 em 1980 para US\$ 9.040 em 2014 (Jabbour; Paula, 2018, p. 14). Dado esse fato, o crescimento chinês - e a própria natureza de seu sistema - é motivo de controvérsias de diversa monta.

Entre outros elementos, a polêmica não é o "modelo" e sim o fato de esse processo ocorrer negando a deus ex machina que condiciona o dinamismo econômico à existência de instituições que garantam a primazia da propriedade privada. ${ }^{1}$ Ao contrário, uma de suas especificidades está - por exemplo - na existência de um Estado que toma a si mesmo o papel tanto, segundo Burlamaqui (2015), "de emprestador de última instância quanto de investidor de primeira instância".

O objetivo deste artigo passa por desenvolver o seguinte argumento:

Um amplo avanço de setor privado na economia não prescindiu da formação de um novo e poderoso setor estatal, notadamente a partir da década de 1990. Em tese, isso significa que a estrutura de propriedade chinesa ainda é muito diferente de outras partes do mundo. Esse processo reflete-se diretamente em um aumento contínuo, desde a segunda metade da década de 1990, do controle governamental sobre os fluxos da renda nacional: de 13,5\% do PIB em 1996 a 37,3\% em 2015 (Naughton, 2017, p. 5; Jabbour; Paula, 2018, p. 17).

Essa citação demonstra a interessante e recente tendência de elevação do papel do Estado sobre a estrutura de propriedade chinesa. Na esteira dessa observação, trabalhos recentes ${ }^{2}$ demostram a grande diferenciação entre

1 O sucesso das Townships and Village Enterprises (TVE's), baseada em direitos de propriedade de difícil compreensão demonstra que a propriedade privada per si não garante dinamismo econômico. Para esse debate sobre as TVE's e o chamado "direito de propriedade", ler: Harry (2001).

2 Segundo Piketty et al. (2017, p. 4-5, apud Jabbour; Paula, 2018, p. 20), (...) China has moved a long way toward private property between 1978 and 2015, but the property regime of the country is still very different than in other parts of the world. In most developed countries, the share of public property in national wealth used to around $15-25 \%$ in the 1960s-1970s and is now close to 0. (...) China has ceased to be communist, but is not entirely capitalist. In effect, the share of public property in China today is somewhat larger than though not comparable to - what it was in West during the 'mixed economy' regime of the post-World War 2 decades ( $30 \%$ in China's mixed economy seems to have strengthened since 2008 financial crises, while it has dropped again in rich countries. ["A China avançou bastante em direção à propriedade privada entre 1978 e 2015, mas o regime de propriedade do país ainda é muito diferente do que em outras partes do mundo. Na maioria dos países desenvolvidos, a participação da propriedade pública na riqueza nacional costumava ficar 
a estrutura de propriedade na China em comparação com outras partes do mundo (grandes conglomerados estatais, empresas de capital misto, propriedade dividida por ações). Esse processo reflete-se diretamente em aumento contínuo, desde a segunda metade da década de 1990, do controle governamental sobre os fluxos da renda nacional (Jabbour; Dantas, 2018), conforme salientado anteriormente. Essa tendência é percebida, também, na queda do aumento da taxa de investimentos do setor privado (de 34,8\% em 2011 para 2,8\% em junho de 2016). Sobre os lucros das empresas estatais, saiu de um crescimento de 15,2\% em 2016 para 23,5\% em $2017 .^{3}$

Logo, nosso trabalho buscará demonstrar que o fenômeno recente marcado por maior protagonismo estatal, sobretudo após 2009, nos permite diagnosticar que a "dinâmica chinesa" é algo que se distancia tanto de uma espécie de "modelo liberal" quanto de um "capitalismo de Estado" strictu sensu. A nosso ver está surgindo na China uma Nova Formação Econômico-Social (NFES) que chamamos de "socialismo de mercado". Ou seja, para nós o "socialismo de mercado" deixou de ser uma abstração, passando a tornar algo real, concreto.

O caráter original do artigo reside na constatação de que essa NFES que surge na China tem um caráter complexo, ou seja, comporta a coexistência (e combinação) de distintos modos de produção. O grande desafio intelectual que nos propomos neste artigo é a compreensão da natureza da coexistência, a coabitação de diferentes modos de produção numa mesma formação social e como essa dinâmica dá caracteres únicos a um processo cuja essência ainda demanda busca e compreensão. Intentaremos avançar, inclusive, em algumas lógicas de funcionamento como forma de dar maior consistência ao argumento central. Aliás, a própria essência do argumento sugere a demonstração das lógicas de funcionamento que dão contornos próprios a essa NFES. Este artigo é um passo importante na citada busca e compreensão da essência do fenômeno chinês, partindo de uma aborda-

entre 15 e 25\% nas décadas de 1960 a 1970 e agora é próxima de 0. (...) A China deixou de ser comunista, mas não é totalmente capitalista. De fato, a participação dos bens públicos na China hoje é um pouco maior do que - embora não comparável - ao que era no Ocidente durante o regime de 'economia mista' das duas décadas pós-Guerra Mundial (os 30\% na economia mista da China parece ter se fortalecido desde a crise financeira de 2008, enquanto caiu novamente nos países ricos."] Nessa mesma linha de raciocínio indicamos o recente trabalho de Naughton (2017).

3 China's Macroeconomic Outlook 2018. Center for Macroeconomic Research at Xiamen University. New York: Springer, 2018. p. 13. 
gem teórica/metodológica nada convencional, nem mesmo entre os marxistas de forma geral.

Além desta introdução, o artigo se divide em outras cinco seções. $\mathrm{Na}$ seção 2, expõe-se a categoria de Formação Econômico-Social (FES) como elemento indispensável de validação teórica. A utilização dessa categoria não guarda serventia somente para sair da superfície acerca da natureza do processo em curso na China. Faz-se necessária sua utilização, também, no sentido de nos diferenciarmos das escolas hegemônicas nos debates sobre as características do fenômeno em tela A seção 3 apresenta nossa interpretação particular sobre o socialismo, seguida da exposição das evidências que sugerem correção ao argumento central do artigo Na seção 4 são demonstradas as cinco lógicas gerais tanto do desenvolvimento histórico quanto do próprio funcionamento da economia chinesa. A seção 5 contrapõe alguns lugares comuns, envolvendo desde a construção do socialismo, até mesmo sua concepção diante dos clássicos dos fundadores do materialismo histórico. Ao final apresentamos algumas conclusões.

\section{Sobre o "Socialismo de Mercado": a episteme e os critérios de validação teórica}

O ponto central de nossa discussão não está em responder se a China é, conforme sua constituição e dirigentes, um Estado socialista ou, trata-se no mais generoso juízo de valor - de uma variante asiática de capitalismo de Estado. Nesse tocante, infelizmente, não pensamento hegemônico pertence à noção para quem o que ocorre na China é uma "restauração capitalista" sob a forma de um "capitalismo de Estado". Não é de se surpreender que um autor da estatura de David Harvey (1992), que não somente alça Deng Xiaoping ao mesmo altar neoliberal de Reagan e Thatcher, ainda constata que "a espetacular emergência da China como uma força econômica global pós-1990 foi uma consequência não intencional do rumo neoliberal no mundo capitalista avançado".

Trata-se de uma observação típica de um esquema pronto, modelar e fotográfico da realidade que guarda muita proximidade com um determinado relativismo pós-moderno em detrimento da objetividade histórica característica de análises baseadas no materialismo histórico (Jabbour, 2012). Abrindo necessário parêntese, no debate de ideias, situamo-nos em um campo 
diferente ao dos postulados atualmente hegemônicos das ciências sociais - entre eles o positivismo clássico, que se expressa sob a forma de, segundo Fernandes (2000) "certo modismo intelectual pós-moderno - que concebe a teoria social como mera narrativa com propósito moral". Logo, segundo Jabbour (2012), “(...) passam a ser colocadas no centro do processo de construção da subjetividade humana a teoria e a prática do relativismo como fio condutor e norte da teoria do conhecimento". De nossa parte, acreditamos que a objetividade e, consequentemente, a visão de processo histórico ainda são os critérios cruciais de validação teórica.

Avançando, dentro dos marcos epistemológicos anteriormente expostos, se admitirmos a China, e seu "socialismo de mercado", como uma formação social complexa, para Harvey, por exemplo, serve a relação feita por Marx entre o desenvolvimento das formações geológicas e o processo de desenvolvimento da sociedade, conforme sugerido em carta enviada a Vera Zasulich

A formação arcaica ou primária de nosso mundo contém em si uma série de camadas de diversas idades, na qual uma está sobreposta à outra; da mesma maneira, a formação arcaica da sociedade [(la formation archaïque de la société)] nos revela uma série de tipos diferentes <que formam entre elas uma série ascendente>, marcando épocas progressivas [(marquant dês époques progressives)]. A comuna rural russa pertence ao tipo mais recente dessa cadeia. O lavrador possui agora a propriedade privada da casa que habita e do quintal que forma o complemento. Eis aí o primeiro elemento dissolvente da forma arcaica [(forme archaïque)], desconhecida aos tipos antigos <e que pode servir de transição da forma arcaica [(de transition de la formation archaique)] (Marx, 2017, p. 17).

\subsection{A categoria marxista de FES como o núcleo basilar de argu- mentação}

Uma tipologia de diagnóstico requer sólidas bases teóricas e conceituais. Logo, nosso principal elemento de validação teórica reside em uma categoria pouco compreendida, redundando - assim - em problemas relacionados a questões próprias de validação teórica, por exemplo. Referimo-nos à categoria de FES. O termo "FES" é pela primeira vez utilizado nos escritos de Marx no Prefácio à Contribuição à crítica da Economia Política: ${ }^{4}$

4 Agradecemos as observações de Sergio Barroso sobre a forma como Marx tratou a categoria de FES. Sobre o trecho citado, duas observações. a) Segundo Sereni (2013, p. 301): É verdade que já muito antes deste trabalho, o conceito (se não o termo) de formação econômico-social se encontra na primeira elaboração completa da concepção materialista da história que Marx e Engels nos deixaram no manuscrito de A ideologia alemã de 1846. Já aqui, 
Nas suas grandes linhas, os modos de produção asiático, antigo, feudal e, modernamente, o burguês podem ser designados como épocas progressivas da formação econômica e social. As relações de produção burguesas são a última forma antagônica do processo social da produção, antagônica não no sentido de antagonismo individual, mas de um antagonismo que decorre das condições sociais da vida dos individuos; mas as forças produtivas que se desenvolvem no seio da sociedade burguesa criam, ao mesmo tempo, as condições materiais para a resolução deste antagonismo. Com esta formação social encerra-se, por isso, a pré-história da sociedade humana (Marx, 2008, p. 48).

\section{Segundo Sereni, é em Lênin que ocorre uma verdadeira "restauração" do sentido da categoria de FES, vejamos:}

Trata-se, em suma por parte destes expoentes máximos do "marxismo da II Internacional", da total incompreensão (quando não, sem mais, do sistemático rechaço) de uma das categorias fundamentais da marxiana concepção materialista da história; e quando se considera o fato de que observações semelhantes poderiam ser repetidas à maioria dos outros expoentes deste mesmo "marxismo da II Internacional" - com as duas únicas e significativas exceções, se não estamos errados, de Antonio Labriola e de Franz Mehring - deixará aparecer melhor a importância central que Lênin dará, desde suas primeiras obras, a esta noção de formação econômico-social, assumindo o valor de uma verdadeira restauração, também neste campo, no da teoria e no da prática do marxismo revolucionário, sem mencionar seu posterior aprofundamento (Sereni, 2013 p. 314).

\section{Segundo Silva (2009), a categoria de FES teve em Emilio Sereni "a sua mais acabada e rica compreensão", citando a seguinte passagem de Sereni:}

(...) a noção (...) se coloca inequivocamente no plano da história, que é (...) o da totalidade e unidade de todas as esferas (estruturais, supraestruturais e outras) da vida social na continuidade e ao mesmo tempo na descontinuidade do seu desenvolvimento histórico (Sereni, 2013, p. 316).

Althusser e Balibar discorrem sobre essa categoria em dois níveis. A pri-

como se pode comprovar facilmente, boa parte do volume I está dedicada a uma rápida passagem através da história mundial, cuja periodização está justamente fundamentada sobre os diferentes graus de desenvolvimento das forças produtivas e das relações de propriedade, isto é, do modo de produção (Weise der Produktion) que caracteriza diferentes épocas. (...). Falta, contudo, como havíamos advertido, em $A$ ideologia alemã o termo Ökonomische Gesellschaftsformation, e em seu lugar se encontra, por enquanto, somente o de Gesellschaftsform (literalmente "forma de sociedade" ou "forma social"), que logo reaparece nos Grundrisse, como, também antes, em muitos outros escritos dos anos entre 1846 e 1857. b) Tendemos a concordar com Gabriele e Schettino (2012), segundo eles no "Prefácio" não é perceptível a diferença entre os conceitos de formação econômico-social e o de modo de produção: "Here, the concepts of SEF and MP are virtually indistinguishable. Yet, room is left for subsequent interpretative approaches that - without undermining the close relationship between the social and the economic spheres which constitutes one of the most fundamental legacies of Marx's thought - tended to differentiate the two concepts, along lines that are consistent with the respective different meanings of the terms "social" and 'production' respectively. ["Aqui, os conceitos de FES e MP são praticamente indistinguíveis. No entanto, sobrou espaço para abordagens interpretativas subsequentes que - sem comprometer a estreita relação entre as esferas social e econômica, que constitui um dos legados mais fundamentais do pensamento de Marx - tendiam a diferenciar os dois conceitos, em linhas consistentes com os respectivos significados diferentes dos termos "social' e' "produção', respectivamente."] 
meira é mais próxima de um esboço de construção da uma "teoria do tempo histórico", como segue

Theory of historical time that allows to establish the possibility of a history of the different levels considered in their 'relative' autonomy". (...) the form of historical existence peculiar to a social formation arising from a determinate mode of production (Althusser e Balibar, 1970, p. 104).5

Althusser e Balibar (1970) chegam a uma definição mais clara e coerente da categoria de FES: "Totality of instances articulated on the basis of a determinate mode of production." 6

Nesse tocante, relacionando as observações de Marx, Althusser, Balibar e Sereni com a utilização da categoria de FES como instrumento de validação teórica, são pertinentes as palavras de Roberts (2017), que em recente artigo, pode-se ler o seguinte:

This brings us to the question of whether China is a capitalist state or not? I think the majority of Marxist political economists agree with mainstream economics in assuming or accepting that China is a capitalist state or not. However, I am not one of them. China is not capitalist. Commodity production for profit, based on spontaneous market relations, governs capitalism. The rate of profit determines its investment cycles and generates periodic economic crises. This does not apply in China. In China, public ownership of the means of production and state planning remain dominant and the Communist party's power base is rooted in public ownership (Roberts, 2017).?

O fundo das razões que levam a maioria dos marxistas a se igualarem aos economistas vulgares dos nossos tempos (neoclássicos) a assumirem posições baseadas em "modelos estáticos" para quem a China é um país capitalista reside no tratamento estático, um "desejo" de classificar e demarcar fenômenos dentro de enquadramentos e categorias aceitas, previamente. Hobsbawn é mais agudo ao afirmar:

5 Versão traduzida: "Teoria do tempo histórico que permite estabelecer a possibilidade de uma história dos diferentes níveis considerados em sua autonomia 'relativa'. (...) a forma de existência histórica peculiar a uma formação social decorrente de um determinado modo de produção".

6 Versão traduzida: "Totalidade das instâncias articuladas sobre a base de um determinado modo de produção".

7 Versão traduzida: "Isso nos leva à questão de saber se a China é um estado capitalista ou não? Eu acho que a maioria dos economistas políticos marxistas concorda com a economia convencional ao assumir ou aceitar que a China é um estado capitalista ou não? No entanto, eu não sou um deles. A China não é capitalista. A produção de mercadorias com fins lucrativos, baseada em relações espontâneas de mercado, governa o capitalismo. A taxa de lucro determina seus ciclos de investimento e gera crises econômicas periódicas. Isso não se aplica na China. Na China, a propriedade pública dos meios de produção e o planejamento estatal permanecem dominantes, e a base de poder do partido comunista está enraizada na propriedade pública." 
(...) o desejo de classificar cada sociedade ou periodo, firmemente, em uma ou outra das categorias aceitas deu como resultado disputas demarcatórias, como é natural quando se insiste em encaixar conceitos dinâmicos dentro de estáticos. Houve, deste modo, muita discussão na China sobre a data de transição da escravidão ao feudalismo [...]. No ocidente, dificuldade semelhante conduziu a debates sobre o caráter dos séculos que vão do XIV ao XVIII (Hobsbawn, 1985, p. 63)

É exatamente disso que se trata: trocar o estático pelo dinâmico. Perceber que na realidade dos modos de produção devemos seguir a trilha sugerida por Ignacio Rangel de perceber que o grau de complexidade de uma sociedade - onde a sua famosa expressão contemporaneidade do não coetâneo (Rangel, 2005) $)^{8}$ é uma regra geral - demanda exercitar a difícil busca apenas do que é essencial, necessário. Para tal, elevar o grau de abstração é essencial, algo que vá além da categoria de modo de produção intentando encontrar a origem de determinada sociedade. Voltando a Lênin, segundo Sereni:

O que é que a maioria dos "marxistas da II Internacional" havia (...) falseado e que Lênin restaurou, aprofundou e desenvolveu na noção marxiana de formação econômico-social? Os materiais mais válidos para responder a indagação nos são oferecidos pelo próprio Lênin, que desde seus primeiros trabalhos - em seu ensaio "Quem são os amigos do povo?", escrito e publicado em 1894 - começa a situar de novo não somente a noção, mas também o termo formação econômico-social no cerne que Marx the havia atribuido como expressão de uma categoria fundamental do materialismo histórico. Sublinhou-se (...) esta categoria expressa a unidade (e, agregaremos, a totalidade) das diferentes esferas: econômica, social, política e cultural da vida de uma sociedade; e a expressa, além disso, na continuidade e ao mesmo tempo na descontinuidade de seu desenvolvimento histórico (Sereni, 2013, p. 314).

Classificamos a República Popular da China como uma sociedade comandada por uma força política decidida a realizar a transição ao socialismo, o que não redunda - de forma alguma - reconhecer a ordem econômica presente como socialista. Samir Amin nos lembra muito bem que:

Mao described the nature of the revolution carried out in China by its Communist Party as an anti-imperialist/anti-feudal revolution looking toward socialism. Mao never assumed that, after having dealt with imperialism and feudalism, the Chinese people had "constructed" a socialist society. He always characterized this

8 Há quem tente explicar a China descrevendo-a desde como um grande campo de trabalhos forçados comandados por "capitalistas selvagens" dentro das regras de um determinado "Partido-Estado" até uma tentativa interessante de "economia mista". A maioria absoluta dos estudos sobre a China que jorra aos milhares nas prateleiras de livrarias não consegue atentar para o fato de que no real está ocorrendo naquele país a construção de um edifício original, onde surgem e ressurgem elementos e instituições de diferentes épocas históricas. Ratificamos aqui que a única razão desse gigantesco processo em andamento na China é observá-lo como parte da história da civilização humana, não se trata de um milagre; muito menos um acaso. 
Exemplo interessante de análise totalizante pode ser percebida por Mamigonian, que percebe no "marxismo de Mao Tsé-Tung" o nível de consequência que pode proporcionar o bom uso das categorias do materialismo histórico a uma formação social complexa. Em suas palavras:

\footnotetext{
Diferentemente do marxismo soviético, herdeiro do marxismo da Europa ocidental, adaptado brilhantemente por Lênin às condições da sociedade russa e à nascente etapa imperialista mundial, o marxismo de Mao, adotando o leninismo, caracterizou-se por uma obsessiva e profunda preocupação pelos destinos da China, que precisava se livrar de qualquer dominio estrangeiro, Inclusive do $I C,{ }^{10}$ recuperar sua antiga grandeza e para isso retomar o papel crucial dos camponeses na vida chinesa, como Li Dazhao ensinou aos seus discipulos. (...) (Mamigonian, 2008, p. 190).
}

Esse raciocínio é complementado da seguinte forma:

A preocupação com o destino da China permitiu: a) retirar o IC do comando da revolução chinesa (1935), b) aliança como Kuomintang para combater a invasão japonesa (1937-45), tornando o PCCh o principal depositário dos interesses nacionais, c) a ofensiva militar na guerra civil de 1946-49 contra o Kuomintang, apoiado pelos EUA, d) a participação decisiva na Guerra da Coreia (1950-53), (...), e) a ruptura da China em relação aos soviéticos (1960) e, f) a aproximação dos EUA (1972), que garantiu a reinserção da China na economia mundial, empreendida sob a liderança de Deng Xiaoping nos anos 80 (Mamigonian, 2008, p. 190).

\section{Sobre o "socialismo de mercado"}

Samir Amin e Armen Mamigonian nos ajudam a deixar mais claro que o sinônimo da percepção do "socialismo de mercado" como uma formação social complexa é assumir, conforme a proposta de Ignacio Rangel, que estamos tratando a unidade de análise como uma formação social complexa. Assim sendo, o "socialismo de mercado" é uma formação que associa via coexistência e coabitação - modos de produção de diferentes épocas históricas em clara unidade de contrários. Não se trata de uma sociedade estruturada no mais alto patamar possível de desenvolvimento humano, ou seja, o socialismo em sua plenitude. Do processo descrito por Amin e

9 Versão traduzida: "Mao descreveu a natureza da revolução realizada na China por seu Partido Comunista como uma revolução anti-imperialista/antifeudal, voltada para o socialismo. Mao nunca assumiu que, depois de lidar com o imperialismo e o feudalismo, o povo chinês "construiu" uma sociedade socialista. Ele sempre caracterizou essa construção como a primeira fase do longo caminho para o socialismo."

10 Internacional Comunista. 
Mamigonian até hoje a China percorreu todo um processo histórico que tem nas reformas econômicas iniciadas em 1978 um típico processo que combina continuidade e ruptura. ${ }^{11}$

A questão que se coloca é: qual modo de produção é dominante? A resposta demanda a interposição de outras questões: qual classe e/ou força política detém o controle dos fatores objetivamente estratégicos sejam eles políticos (a força política representativa da classe social que exerce controle do poder do Estado) ou econômicos (o modo de produção que detém o poder real tanto sobre os ferramentais fundamentais do processo de acumulação - de juros, taxa câmbio e sistema financeiro estatal - quanto na promoção de deslocamento e concentração do próprio setor produtivo em indústrias-chave e possibilitando crescimento e desenvolvimento a partir da geração dos efeitos de encadeamento industrial aos demais modos de produção)? Para tal é sugestiva a seguinte passagem, de Fan et al.:

The socialist foundation of China's economic system is the unconditional supremacy of the Chinese Communist Party. Consistent with Marxist-Leninist tradition, the Party directs the law. Regulations, laws, and administrative rulings are applied in accordance with current Party policy. Just as a Party position corresponds directly to each key position in government, a Party hierarchy parallels corporate governance in banks, SOEs, listed non-SOEs, hybrid enterprises, joint ventures, and sufficiently large private businesses. Party cells throughout business enterprises constitute parallel internal accountability systems to those established by enterprises themselves, keeping an enterprise's Party Secretary and Party Committee up-to-date and able to provide timely advice to its CEO and board. Imported corporate governance regulations, mandating independent directors and the like essentially ignore Party involvement in enterprise governance (Fan et al., 2011, p. 11). ${ }^{12}$

11 Continuidade no sentido dos rumos e objetivos que levaram o PCCh ao poder em 1949 e ruptura com o método e as formas que desde meados da década de 1950 passaram a prevalecer por todo o corpo social chinês.

12 Versão traduzida: "O fundamento socialista do sistema econômico da China é a supremacia incondicional do Partido Comunista Chinês. Consistente com a tradição marxista-leninista, o Partido dirige a lei. Regulamentos, leis e decisões administrativas são aplicados de acordo com a política atual da Parte. Assim como uma posição do Partido corresponde diretamente a cada posição-chave no governo, uma hierarquia do Partido é paralela à governança corporativa em bancos, Empresas estatais, Empresas estatais não listadas no mercado de ações, empresas híbridas, joint ventures e empresas privadas suficientemente grandes. As células do partido em todas as empresas constituem sistemas paralelos de responsabilidade interna aos estabelecidos pelas próprias empresas, mantendo atualizados o Secretário e o Comitê do Partido de uma empresa e capazes de fornecer conselhos oportunos ao seu CEO e diretoria. Os regulamentos de governança corporativa importados, que obrigam diretores independentes e semelhantes, ignoram essencialmente o envolvimento do Partido na gover- 
Por outro lado, existe uma grande diferença entre classificar a China como um país capitalista e reconhecer que o capitalismo, seja ele privado ou de Estado, existe no país como um importante - e poderoso - modo de produção. ${ }^{13}$

Nesse sentido, a realização da transição em uma formação social complexa como a chinesa implica reconhecer que a unidade de contrários aludida anteriormente se expressa na convivência dos seguintes modos de produção: ${ }^{14}$

a) economia natural de subsistência: é a estrutura que, apesar de estar em franca decomposição, ainda concentra toda a população que vive abaixo da linha da pobreza na China. Sua maioria é composta por populações de minorias étnicas. Seu número absoluto é confuso. O próprio governo anuncia variações neste número, que fica entre 30 e 43 milhões de pessoas; ${ }^{15}$

b) pequena produção mercantil: caracterizada pela produção agrícola de pequeno porte (familiar) voltada ao mercado, principalmente nas cidades de porte médio. Porém, é muito comum perceber a existência desse setor na periferia de grandes cidades. Apesar dos avanços em matéria de mecanização da produção agrícola na China, estima-se que 300 milhões de pessoas ainda trabalhavam em atividades agrícolas em 2012.

c) capitalismo privado: setor criado, guiado e formado sob as asas do Partido Comunista da China (PCCh). A existência dessa estrutura/formação social na China é motivo de grandes exageros e equívocos sobre seu poder e papel na economia e na sociedade chinesa em geral. Um bom indicativo dessa tendência pode ser assim observado: "As privatizações e a abertura de capital de empresas estatais e coletivas a partir de meados dos anos 1990 foram o primeiro movimento massivo de concentração de capital em mãos privadas na China" (Nogueira, 2018, p. 7).

Apesar de concentrar grande parcela de riqueza, renda e grande poder de barganha junto ao Estado, não se trata de uma classe capaz suficiente para se tornar "classe dominante" como nos países capitalistas.

nança corporativa."

13 Sobre a análise dos principais mecanismos utilizados para concentração de capital e formação de uma classe capitalista doméstica na China, ler Nogueira (2018). Raciocínio semelhante ao de Nogueira sobre a influência dos capitalistas domésticos chineses, porém sob um ponto de vista de um geógrafo, pode ser encontrado em Lim (2014).

14 Construção amplamente baseada em Lênin (1964).

15 O plano é eliminar completamente a existência de população vivendo em tais condições até 2020. Vale lembrar, a título de exemplo, que segundo o Banco Mundial a porcentagem da população chinesa vivendo em condições de extrema pobreza caiu de $88 \%$ em 1981 para $0 \%$ em 2022. 
d) capitalismo de Estado: ${ }^{16}$ Trata-se de uma formação com visíveis contornos nas relações de dependência do capitalismo privado com as políticas de Estado, por exemplo, como beneficiária dos efeitos de encadeamento gerados pelas corporações estatais, acesso a crédito em bancos estatais etc.

e) socialismo: Formação social que define a própria natureza do Estado Nacional chinês. Tendo o Partido Comunista a força política que controla o Estado, que por sua vez detém o controle dos fatores objetivamente estratégicos. Observemos a sugestiva citação:

State-owned and state-holding enterprises are now less numerous, but much larger, more capital- and knowledge-intensive, more productive and more profitable than in the late 1990s. Contrary to popular belief, especially since the mid-2000s, their performance in terms of efficiency and profitability compares favorably with that of private enterprises. The state-controlled sub-sector constituted by state-holding enterprises, in particular, with at its core the 149 large conglomerates managed by SASAC, is clearly the most advanced component of China's industry and the one where the bulk of in-house R\&D activities take place (Gabriele, 2009, p. 17). ${ }^{17}$

\subsection{Os elementos de mediação entre as diferentes estruturas/for- mações sociais}

O processo de desenvolvimento não ocorre por impulsos, ou raramente ocorre dessa forma. Muito menos se trata de um processo de "desenvolvimento equilibrado" como nos mostraram Rosenstein-Rodan e Nurske em suas famosas e pioneiras obras sobre as economias externas e o crescimento equilibrado. ${ }^{18}$ Ignacio Rangel e Albert Hirschman foram exímios críticos dessa concepção. Em ambos o desenvolvimento é um processo de saltos não de um ponto de equilíbrio a outro, e sim sob forma de saltos entre

16 É muito comum associar a China como uma experiência de "capitalismo de Estado". Essa associação é consequência da separação entre politica e economia na análise do processo. Para nós é uma fase do desenvolvimento capitalista em países onde o Estado exerce grande papel, porém tem como formaçãolestrutura dominante as empresas privadas.

17 Versão traduzida: "As empresas estatais e estatais são agora menos numerosas, mas muito maiores, mais intensivas em capital e conhecimento, mais produtivas e mais lucrativas do que no final dos anos de 1990. Contrariamente à crença popular, especialmente desde meados da década de 2000, seu desempenho em termos de eficiência e lucratividade se compara favoravelmente ao das empresas privadas. O subsetor controlado pelo estado, constituído por empresas estatais, em particular, com os 149 grandes conglomerados administrados pela SASAC, é claramente o componente mais avançado da indústria chinesa e aquele em que a maior parte das atividades internas de pesquisa e desenvolvimento tomam lugar."

18 Sobre a tese do "desenvolvimento equilibrado", ler Rosenstein-Rodan (1943) e Nurske (1953). 
pontos de desequilíbrios. Nas palavras de Rangel:

As pessoas podem fazer uma ideia um pouco romântica do desenvolvimento econômico, como se ele fosse um paraíso de estabilidade, bem-estar e paz. É preciso abandonar desde logo essas ilusões. No Brasil, como em todos os países, o desenvolvimento é um processo doloroso, repleto de privações, conflitos e inquietações. Tais inquietações são, ao que parece, uma matéria-prima do desenvolvimento, (...). Uma economia em desenvolvimento não resolve um problema sem criar outro ainda maior. Salta ininterruptamente de um desequilibrio a outro (Rangel, 2005, p. 41).

Esse raciocínio cabe perfeitamente ao processo de desenvolvimento em uma formação social complexa como já demonstramos aqui, sobre a China. Diferentes modos de produção representando, cada um deles, em um determinado estágio de desenvolvimento da própria humanidade requerem a existência de elementos de mediação entre as diferentes dinâmicas e respectivas velocidades e movimentos característicos de cada estrutura/formação social. São eles:

a) economia natural: em acelerado processo de decomposição;

b) economia de mercado: onde convive e compete entre si a economia privada de variado tamanho, desde a pequena produção mercantil até a grande produção de escala de tipo capitalista. Porém, diferentemente de outras economias de mercado capitalistas, nesse mercado predominam os grandes conglomerados empresariais e sistema financeiro estatais, que, por sua vez, podem ser consideradas como o coração (os 149 conglomerados empresariais estatais) e a alma (sistema financeiro estatal) da NFES ("socialismo de mercado");

c) comércio exterior: sob o socialismo o comércio exterior é uma instituição pública, planificada e de Estado (Jabbour; Dantas, 2017). É onde predominam relações de novo tipo no que diz respeito ao comércio exterior de tipo capitalista. Nesse aspecto - também com o objetivo de demonstrar os impactos de determinados movimentos à transição chinesa - deve ser elencado o papel da recolocação comercial, política e financeira no mundo por parte da China.

\section{A economia política do "socialismo de mercado": as lógicas que regem seu movimento}

Não negamos aqui que a construção teórica que estamos tentando construir é parte de uma crítica ao etapismo que vigorou, e ainda exerce influên- 
cia, nas elaborações marxistas sobre a transição do capitalismo ao socialismo. Indicar o "socialismo de mercado" como uma nova FES não é somente parte de um esforço de desvendar as lógicas que regem a construção do socialismo em formações sociais complexas.

Esse mesmo raciocínio vale à nossa leitura sobre o "socialismo de mercado"; um esforço para compreender a China e descobrir a lógica fundamental de seu processo de desenvolvimento. Buscamos adaptar o materialismo histórico às peculiaridades de uma formação social complexa como a chinesa.

Expostas tais indicações e tendo clareza de estarmos tratando de uma formação social complexa, o passo agora é extrair as lógicas de funcionamento da economia chinesa. O "socialismo de mercado" é, na verdade, a resposta, quase que um "método de análise", que encontramos a essas e outras questões que vão surgindo. Trata-se de nossa interpretação particular sobre a razão e o significado do desenvolvimento das forças produtivas que transcorre na China, cuja contrapartida é o poder político exercido pelo PCCh.

Uma justa questão que se coloca: qual a diferença entre o "socialismo de mercado" e o capitalismo, já que a existência de um largo setor público também pode ocorrer sob o capitalismo? A passagem seguinte é esclarecedora:

The State is endowed with a high degree of direct and indirect control of the means of production, and, as a result, social production relations are different from those prevalent in capitalism. This statement implies that, at a lower level of abstraction, a "market socialist" and a capitalist system differ essentially in two key aspects. The first one is that in a market socialist system the role of the State is both quantitatively larger and qualitatively superior, thereby allowing the public sector as a whole to exert an overall strategic control over the country's development path, especially in crucial areas such as setting the economy-wide rate of the accumulation and determining the speed and direction of technical progress. The second difference is that in a market socialist system, although capitalists endowed with private ownership rights on some means of production do exist, they are not strong enough to constitute a hegemonic and dominant social class, as it happens in "normal" capitalist countries (Gabriele; Schettino, 2012, p. 32). ${ }^{19}$

19 Versão traduzida: "O Estado é dotado de um alto grau de controle direto e indireto dos meios de produção e, como resultado, as relações sociais de produção são diferentes daquelas prevalecentes no capitalismo. Essa afirmação implica que, em um nível mais baixo de abstração, um sistema "socialista de mercado" e um sistema capitalista diferem essencialmente em dois aspectos principais. A primeira é que, em um sistema socialista de mercado, o papel do Estado é quantitativamente maior e qualitativamente superior, permitindo ao setor público como um todo exercer um controle estratégico geral sobre o caminho de desenvolvimento do país, especialmente em áreas cruciais, como a taxa de acumulação em toda a economia e a determinação da velocidade e direção do progresso técnico. A segunda diferença é que, em um sistema socialista de mercado, embora existam capitalistas com direitos de propriedade privada sobre alguns meios de produção, eles não são fortes o suficiente para constituir uma classe social hegemônica e dominante, como acontece nos países capitalistas 'normais'." 
Perceber que na China convivem vários modos históricos de desenvolvimento nos levou a intentar a descoberta de como as lógicas dos vários modos de produção coetâneos se articulam, auxiliam ou limitam umas às outras. Após 40 anos do início do processo de reforma e abertura na China já é possível perceber ao menos cinco lógicas de funcionamento, conforme:

a) Logo de imediato, ao assumirmos que a formação social chinesa é uma miríade onde existem diferentes modos de produção e suas devidas lógicas de funcionamento, devemos admitir, como uma lógica de funcionamento, que tais formações não se limitam a coexistir. Coabitam em conflito e exercem pressão - uma sobre a outra - aberta entre si.

Por exemplo, a expansão da economia de mercado pressiona e impõe a tendência ao desaparecimento da economia natural de subsistência; o mesmo ocorre na pressão que a transformação da agricultura em um ramo da indústria exerce sobre a pequena produção mercantil. O mesmo ocorre entre o setor socialista da economia e a capitalista privada, com a última sendo pressionada diante da tendência de cada vez maior centralização da grande produção industrial nos 149 conglomerados empresariais estatais e o já citado processo de aumento contínuo do controle governamental sobre os fluxos da renda nacional.

b) A lei do valor não é passiva de superação sob o "socialismo de mercado" visto como parte do início do processo histórico de construção do socialismo. ${ }^{20}$ Acreditamos ser essencial essa observação àqueles que, como nós, guardam preocupações sobre os limites da planificação econômica em formações sociais onde pedaços de capitalismo privado não somente estão presentes, como também exercem pressão sobre a formação dominante (socialismo); ${ }^{21}$

c) Num primeiro momento, identificamos (Jabbour; Dantas, 2017) que as reformas econômicas permitiram o surgimento de um largo setor privado convivendo com o preexistente setor estatal. A nós essa coabitação demanda "uma contínua reorganização de atividades entre os setores estatal e privado da economia" (Jabbour; Dantas, 2017). ${ }^{22}$ Tal diagnóstico avançou

20 A nós o "socialismo de mercado" é sinônimo do que se convencionou chamar de "etapa primária do socialismo". Escrevemos sobre isso em Jabbour et al. (2017).

21 Sobre os limites da planificação sob o socialismo de mercado, ler Gabriele (2016).

22 Também cabe ao caso chinês a seguinte passagem de Rangel (1985, p. 5): "Em todos os períodos da história (...) a economia sempre teve, ao lado do setor privado, o setor público. De tempos em tempos, a distribuição de atribuições entre esses setores é posta em causa e (...), procedemos a uma redistribuição dessas atribuições entre os dois setores. Isso ajuda a superar a crise e a abrir novo período de desenvolvimento. Ora, não há como supor que essa dialética se tenha esgotado." 
demonstrando que essa contínua reorganização de atividades ocorre mediada pelo surgimento cíclico de instituições que delimitam uma contínua reorganização de atividades entre os setores estatal e privado da economia (Jabbour; Paula, 2018). ${ }^{23}$

d) Existe uma regularidade nesse processo cíclico de reorganização de atividades entre os dois setores. $O$ crescimento do setor privado não ocorre em detrimento de uma diminuição do papel do Estado. Existe, no concreto, uma recolocação estratégica do Estado. Vejamos:

A reação chinesa à crise de 2008 demonstrou que houve um processo caracterizado pela construção de um Estado que reúne a capacidade tanto para agenciar politicas de socialização do investimento quanto de investidor e emprestador não prescindiu somente da indução à existência de um setor privado concomitante. Foi além, promovendo deslocamento e concentração de seu próprio setor produtivo em indústrias-chave, que combinam alta produtividade com grandes retornos em escala (Jabbour; Paula, 2018, p. 8).

Já o setor privado, longe de ser o protagonista do processo, não passa de um setor ancilar das corporações estatais ${ }^{24}$;

e) É de compreensão geral sobre algo que pode ser considerado permanente em uma economia capitalista que períodos de crise se alternam com períodos de crescimento. Historicamente foram sendo construídas alternativas de solução a essa instabilidade cíclica: no capitalismo pela via dos gastos públicos, e no socialismo o ciclo é enfrentado a partir do planejamento ${ }^{25}$ e seus ferramentais e mecanismos. Dessa forma, o planejamento guarda razão sob forma de uma lógica econômica essencial no "socialismo de mercado". 26

23 Aprofundamos essa constatação em Jabbour e Paula (2018).

24 Interessante notar o fato - que distingue a experiência desenvolvimentista chinesa de outros casos - de o surgimento de novos marcos institucionais não incorrer, ao longo do processo de industrialização, em solução de descontinuidade (Medeiros, 2013, p. 435, apud Jabbour e Paulo, 2018, p. 7).

25 Segundo Harnecker (2012, p. 243): “(...) without participatory planning there can be no socialism, not only because of the need to end the anarchy of capitalist production, but also because only through mass engagement can society truly appropriate the fruits of its labor. The actors in participatory planning will vary according to different levels of social ownership."

26 Sobre o planejamento cabem as palavras de Rangel (2005, p. 453): "Essa ciência e essa arte se converteram, desde já, na rainha de todas as artes e de todas as ciências de nosso tempo, porque é graças a elas que o enorme acervo de conhecimento humano acumulado ao longo dos séculos ganha novo sentido, produzindo novos e surpreendentes resultados. E, sobretudo, é graças a elas que a sociedade humana se torna realmente capaz de vontade, habilitando-se a escolher o ritmo e o sentido de sua marcha." 


\section{Sobre o socialismo: enfrentar senso comum e a "dialética de Saturno"}

Não é difícil perceber que o senso comum projetou, com sucesso, uma versão da China como um país capitalista. Afora os juízos pejorativos de valor amplificados pela grande mídia, retrato tragicômico dos interesses do imperialismo. Temos plena clareza da pouca aderência que a nossa visão daquele processo suscita. Algumas considerações são importantes.

Sabemos não ser tarefa fácil propor a construção de uma teoria como subsídio capaz de explicar esse "socialismo de mercado" envolto, e parte principal, em um mundo em plena transformação. E que tem no núcleo dessa transformação uma FES de novo tipo, socializante, cujo país-sede está muito próximo de se transformar no líder de um novo centro do sistema que transita do Atlântico Norte ao Leste Asiático. Sendo claros: o país de terceiro maior tamanho territorial e, também, o mais populoso do mundo e que advoga o caráter socialista de sua experiência está passando a dar as cartas no sistema mundial. Voltemos assim à polêmica sobre o socialismo chinês, polêmica esta que tende a se estender ao longo, pelo menos, da próxima década. O déficit de visão de processo histórico é parte do problema. Nesse sentido, é bom lembrar que:

Assim como a transição feudalismo-capitalismo durou séculos, (...), igualmente
a transição capitalismo-socialismo está se fazendo ao longo de séculos. Os ger-
mes do capitalismo nas cidades italianas e flamencas (séculos XIII e XIV) não
foram suficientes e só muito mais tarde as relações capitalistas de produção na
Inglaterra tiveram forças suficientes para romper a carapaça feudal (Revolução
puritana) (...). Ora, quando Marx e Engels imaginaram a vitória da revolução
simultaneamente na Inglaterra, França e Alemanha, criando um núcleo socia-
lista mundial ao redor do qual poderiam girar e se incorporar os demais países
(inclusive a Rússia, com sua base agrária igualitarista), estavam se baseando
nas revoluçôes de 1848 que agitaram a Europa (...). Mas a realidade mostrou-
-se diferente, pois quando da conjuntura revolucionária mundial de $1917-1923$
somente na Rússia a revolução saiu-se vitoriosa, em parte graças às ideias de
Lênin, que conseguiram impulsionar para frente o pensamento marxista radical
(Mamigonian, 2001, p. 7).

Desde seu surgimento já eram visíveis as diferenças de opinião e, de concepção, sobre a natureza do socialismo. Desde Lassale (pela "direita"), Blanqui (pela "esquerda") e Marx, cuja visão de conjunto o levou a adotar sempre posições mais centristas. Ora, não é de se imaginar que o mesmo ocorre quando o assunto é a China. E foi frequente com relação à União Soviética. Essas divisões podem ser explicadas da seguinte forma: 
A dialética com base na qual "Saturno devora seus filhos" não é certamente uma característica da exclusiva da Revolução de Outubro: a unidade coral que preside a derrubada de um regime antigo agora malquisto pela maioria da população inevitavelmente se racha ou se dispersa no momento em que se trata de decidir sobre a nova ordem a estabelecer. Isso vale também para as Revoluções inglesa e estadunidense (Losurdo, 2010, p. 47).

O socialismo levanta expectativas de tipo messiânicas. Eis a fonte por onde age de forma violenta a "dialética de Saturno". Não é incomum relacionar o socialismo como a expressão de uma sociedade onde a contradição desaparece levando consigo as desigualdades sociais, a economia monetária, as fronteiras entre o "meu" e o "seu". Sobre a China, o "socialismo de mercado" dentro de uma visão talmúdica é sinônimo de "traição" aos princípios do marxismo. Nesse caso, a "dialética de Saturno" se expressa na confusão entre os que percebem a economia de mercado como uma categoria histórica e aqueles que colocam um sinal de igualdade entre mercado e capitalismo. O igualitarismo muito comum no movimento comunista leva a redução de Marx à de mais um pensador da "questão social" ou, no máximo, um ricardiano menor.

Retornando, já no Manifesto comunista, nos lembram Marx e Engels que: Nada é mais fácil do que recobrir o ascetismo cristão com um verniz socialista. Noções igualitaristas devem ser enfrentadas nessa tarefa de construção de uma nova teoria a que propomos. Nesse sentido, a seguinte passagem de Losurdo é interessante e guarda essencialidade:

$\mathrm{Na}$ Fenomenologia do Espírito, Hegel coloca em evidência a aporia contida na ideia de igualdade material que está no fundamento da reivindicação da "comunhão de bens". Quando se põe em prática uma satisfação igual das necessidades diferentes dos individuos, é claro que se verifica uma desigualdade em relação à "quota de participação", ou seja, à distribuição dos bens; se, porém, se faz uma "distribuição igual" dos bens, então é claro que se torna desigual nos individuos a "satisfação das necessidades" (sempre diferentes) (Losurdo, 2010, p. 57-58).

É evidente, portanto, a impossibilidade da "promessa" de igualdade material contida na noção de "comunhão de bens". Losurdo confirma esse raciocínio conforme segue:

Marx, que conhecia muito bem a Fenomenologia, resolve a dificuldade correspondente (na Crítica ao Programa de Gotha) aos dois modos diferentes de declinar a "igualdade" (que é sempre parcial e limitada) a dois estados diferentes de desenvolvimento da sociedade pós-capitalista: no estágio socialista, a distribuição segundo um "direito igual", ou seja, retribuindo com medida igual o trabalho fornecido por cada cidadão singular e sempre mais diferente, produz uma evidente desigualdade na retribuição e na renda; nesse sentido o "direito igual" não é outra coisa senão o "direito da desigualdade". No estágio comunista, a satisfação igual das diferentes necessidades comporta também uma desigualdade na dis- 
tribuição dos recursos, só que o enorme desenvolvimento das forças produtivas, satisfazendo igualmente as necessidades de todos, torna tal desigualdade sem importância (Losurdo, 2010, p. 58).

Duas consequências podemos extrair dessas duas passagens: a) no socialismo, a igualdade material não é possível; e b) no comunismo essa "igualdade material" não tem sentido. Daí a ênfase dos fundadores do socialismo científico ao comprometimento dos trabalhadores com o desenvolvimento das forças produtivas.

Como forma de síntese do que discutimos sobre o socialismo, encerramos esta seção com a seguinte citação:

O proletariado utilizará sua supremacia política para arrancar pouco a pouco todo capital à burguesia, para centralizar todos os instrumentos de produção nas mãos do Estado, isto é, do proletariado organizado em classe dominante, e para aumentar, o mais rapidamente possível, o total das forças produtivas (Marx; Engels, 1998, p. 56).

\section{Conclusões}

Concluímos este artigo de forma muito satisfatória. Apresentamos a hipótese de que existe um movimento na China, notadamente após 2009, onde o maior protagonismo do Estado nas grandes questões que envolvem o processo de acumulação, o "socialismo de mercado", já pode ser considerado como uma NFES. Trata-se de um processo que, como já lançado na própria Introdução, desde a segunda metade da década de 1990 já conformava um processo de elevação do controle estatal sobre os fluxos de renda no país. Na verdade, o Estado chinês controla cerca de $30 \%$ da riqueza nacional, um nível muito maior que o apresentado em alguns países ocidentais na chamada "Golden Age" (1950-1980) do capitalismo: em países como os EUA, Alemanha, França e Grã-Bretanha esse controle variou entre $15 \%$ e $25 \%$ (Piketty et al., 2017).

Porém, conforme demonstrado, foi a resposta à crise de 2009 na qual esse movimento demonstrou concretude com o Estado, sendo o financiador (via bancos públicos) e executor (via empresas estatais) de um pacote fiscal de US\$ 589 bilhões. Ora, algo de muito diferente estava ocorrendo à China que poderia ter passado despercebido dos analistas, em geral, e dos marxistas, em particular.

Ao começarmos a aviltar a hipótese aqui levantada e demonstrada sugerimos que a China, e sua dinâmica de desenvolvimento, estava - de certa 
maneira - distante de ser uma variante de capitalismo liberal ou de "Estado". A possibilidade teórica dessa interpretação buscou subsídio em uma categoria marxista muito pouco conhecida e/ou mesmo utilizada: a categoria de formação econômico-social. Por via de desenvolvimento, citações e demarcações de fronteira com outros polos de pensamentos, buscamos expor que essa categoria é única quando o sentido é a busca da gênese de processos complexos. Partindo dessa categoria de análise, avançamos na formulação de nosso argumento.

A dinâmica da coexistência em "unidade de contrários" entre diferentes modos de produção foi fundamental, principalmente por indicar que o modo de produção socialista, representado pela própria natureza do poder político estatal e da estrutura financeira e produtiva, é dominante em meio a outros modos de produção. É bom notar que não trabalhamos com categorias apriorísticas, entre elas a da existência de um "socialismo puro". Não existe "socialismo puro" na China, ao contrário. A dinâmica dos diferentes modos de produção indica interação plena entre eles, e amplamente contraditória. Contradições tais que podem ser exprimidas no fato de a China conviver com contradições de variados graus, entre elas as contradições sociais, ambientais etc...

Mas essa indicação não é suficiente. Essa NFES engendra lógicas de funcionamento muito particulares, que a distingue das lógicas dos países capitalistas. Cinco lógicas de funcionamento foram apresentadas e exemplificadas, dando substância ao argumento do trabalho, são elas: a) os diferentes modos de produção não se restringem a coexistir, mas convivem em "unidade de contrários"; b) A lei do valor não é passiva de superação sob o "socialismo de mercado", visto como parte do início do processo histórico de construção do socialismo; c) a existência de dois setores, o estatal e o privado, demanda contínua reorganização de atividades entre esses setores. Essa contínua reorganização de atividades ocorre mediada pelo surgimento cíclico de instituições que delimitam uma contínua reorganização de atividades entre os setores estatal e privado da economia; d) Existe uma regularidade nesse processo cíclico de reorganização de atividades entre os dois setores. $O$ crescimento do setor privado não ocorre em detrimento de uma diminuição do papel do Estado. Existe, no concreto, uma recolocação estratégica do Estado ao ampliar seu papel de forma qualitativa; e e) $O$ planejamento guarda razão sob forma de uma lógica de funcionamento essencial no "socialismo de mercado". 
Por fim, sob a rubrica da "dialética de Saturno" trouxemos à tona um antigo debate sobre as expectativas criadas durante o processo de construção do socialismo e a validade dessa sadia polêmica à compreensão da China atual. Para tanto, lançamos mão de citações, também, de clássicos como Hegel, Marx e Engels. A nós, nunca foi tão fundamental voltarmos aos "clássicos" para buscar explicações para fenômenos novos e complexos.

Temos clareza da complexidade do tema e das polêmicas envolvidas. $\mathrm{Na}$ verdade, este artigo encerra um primeiro e grande passo. Já é passado o momento de se discutir a China fora de parâmetros aceitos a anteriori por todos os principais lados do debate. Este artigo se coloca como parte alternativa, outsider da própria, e necessária, polêmica.

\section{Referências}

ALTHUSSER L.; BALIBAR, E. Reading Capital. Paris: NLB, 1970.

AMIN, S. China 2013. Monthly Review, v. 64, n. 10 (8), p. 15-27, 2013.

BURLAMAQUI, L. Finance, development and the Chinese entrepreneurial state: A Schumpeter-Keynes-Minsky approach. Brazilian Review of Political Economy, v. 4, n. 141, p. 728744, 2015.

CHINA's Macroeconomic Outlook 2018. Center for Macroeconomic Research at Xiamen University. New York: Springer, 2018.

COUTINHO, L. A 4a Revolução Industrial: criativa ou disruptiva para o Brasil? Princípios, n. 150 , p. $30-38,2018$.

ENGELS, F. Anti-Dühring. São Paulo: Boitempo, 2015.

FAN, J; MORCK, B; YEUNG, B. Capitalizing China. NBER Working Paper, n. 17.687, December, 2011.

FERNANDES, L. O enigma do socialismo real. Rio de Janeiro: Mauad, 2000.

FERNANDES, L. A revolução bipolar. São Paulo: Anita Garibaldi/Editora PUC-Rio, 2017.

GABRIELE, A. The role of state in China's industrial development: A reassessment. MPRA Working Paper, n. 1.451, Apr., 2009.

GABRIELE, A.; SCHETTINO, F. Socialist market economy as a distinct SEF internal to the modern MP. New Proposals: Journal of Marxism and Interdisciplinary Inquiry, v. 5, n. 2, p. 20 50, 2012.

GABRIELE, A. Lessons from enterprise reforms in China and Vietnam. MPRA Working Paper n. 71.026, 2016.

HARNECKER, M. Question 5: Social and Long-Term Planning? Science \& Society, v. 76, n. 2, p. 243-266, 2012.

HARRY, W. Property Rights and Legal Reform in Township and Village Enterprises in China. 
Asian-Pacific Law \& Policy Journal, v. 1, n. 2, p. 229-258, Winter, 2001.

HARVEY, D. Condição pós-moderna. São Paulo: Loyola, 1992.

HOBSBAWM, E. "Introdução". In: MARX, K. (1985). Formações econômicas pré-capitalistas. São Paulo: Paz e Terra, 1985.

JABBOUR; DANTAS (2018). O socialismo de mercado e suas lógicas de funcionamento. Carta Capital online, 10/08/2018. Disponível em: <https://www.cartacapital.com.br/blogs/ brasil-debate/o-socialismo-de-mercado-e-suas-logicas-de-funcionamento/>. Acesso em: $15 / 08 / 2017$

JABBOUR, E. China hoje: Projeto Nacional, Desenvolvimento e Socialismo de Mercado. São Paulo: Anita Garibaldi/EDUEPB, 2012.

JABBOUR, E.; DANTAS, A. The political economy of reforms and the present Chinese Transition. Brazilian Journal of Political Economy, v. 37, n. 4, p. 789-807, 2017.

JABBOUR, E; DANTAS, A; BELMONTE, A. Ciclos econômicos, desenvolvimento e mercado: anotações sobre o socialismo e a 'etapa primária'. In: BERTOLINO, O; MONTEIRO, A. (Org.). 100 anos da Revolução Russa: legados e lições. São Paulo: Anita Garibaldi, 2017.

JABBOUR, E.; PAULA, L. F. A China e a "socialização do investimento": uma abordagem Keynes-Gerschenkron-Rangel-Hirschman. Revista de Economia Contemporânea, v. 22, n. 1, p. 1-23, 2018.

JIN, C. An Economic Analysis of the Rise and Decline of Chinese Township and Village Enterprises. New York: Palgrave, 2017.

KHOO, H. Examining Xi Jinping's speech on the method of Karl Marx. China.org.cn, 27/06/2016. Disponível em: <http://www.china.org.cn/opinion/2016-06/27/content_38751141.htm>. Acesso em: 12 May 2017.

KHUONG, V. The Dynamics of Economic Growth: Policy Insights from Comparative Analyses in Asia. Cheltenham: Edward Elgar, 2013.

LENIN, V. The tax in kind (the significance of the new policy and its conditions). In: LENIN, V. Collected Works. Moscow: Progress Publishers, v. 32, p. 326-365, 1964.

LIM, K. 'Socialism with Chinese characteristics': Uneven development, variegated neoliberalization and the dialectical differentiation of state spatiality. Progress in Human Geography, v. 38, n. 2, p. 221-247, 2014.

LOSURDO, D. Stálin - história crítica de uma lenda negra. São Paulo: Boitempo, 2010.

MAMIGONIAN, A. Capitalismo e socialismo em fins do século XX (visão marxista). Ciência Geográfica, v. 7, n. 18, p. 4-9, 2001.

MAMIGONIAN, A. A China e o marxismo: Li Dazhao, Mao e Deng. In: DEL ROIO, M. (Org.). Marxismo e Oriente: quando as periferias tornam-se os centros. Marília: Ícone, 2008.

MARX, K. Contribuição à crítica da Economia Política. São Paulo: Expressão Popular, 2008.

MARX, K. Crítica ao Programa de Gotha. São Paulo: Boitempo, 2012.

MARX, K. Carta a Vera Zasulich, 1881. In: SHANIN, T. Marx tardio e a via russa: Marx e as periferias do capitalismo. São Paulo: Expressão Popular, 2017.

MARX, K; ENGELS, F. Manifesto comunista. São Paulo: Boitempo, 1998. 
MEDEIROS, C. Padrões de investimento, mudança institucional e transformação estrutural na economia chinesa. In: BIELSCHOWSKY, R. (Org.). Padrões de desenvolvimento econômico: América Latina, Ásia e Rússia (1950-2008). Brasília: CGEE, 2013.

NAUGHTON, B. Is China socialist? Journal of Economic Perspectives, v. 31, n. 1, p. 3-24, 2017.

NOGUEIRA, I. Estado e capital em uma China com classes. Revista de Economia Contemporânea, v. 22, n. 1, p. 1-23, 2018.

PIKETTY, T; YANG, L.; ZUCMAN, G. Capital accumulation, private property and rising inequality in China. NBER Working Paper, n. 23.368, Apr. 2017.

RANGEL, I. Dualidade básica da economia brasileira. In: RANGEL, I. Obras reunidas. Rio de Janeiro: Contraponto, 2005.

RESCH, R. Althusser and the Renewal of Marxist Social Theory. Los Angeles: University of California Press, 1992.

ROBERTS, M. China: Three models of development. Michael Roberts Blog, 2018. <https:// thenextrecession.files.wordpress.com/2015/09/china-paper-july-2015.pdf>. Acesso em 20 June 2018.

ROBERTS, M. Xi takes full control of China's future. Redline: Contemporary Marxist Analysis, 2017. <https://rdln.wordpress.com/2017/10/26/xi-jinping-thought-and-the-natureof-china-today/>. Acesso em: 11 May 2019.

ROSS, J. Deng Xiaoping and John Maynard Keynes. Soundings, n. 46, p. 25-47, 2010.

SANTOS, M. Sociedade e espaço: a formação social como teoria e como método. Boletim Paulista de Geografia - BPG, n. 54, p. 81-99, 1977.

SERENI, E. De Marx a Lênin: a categoria de "formação económico-social". Meridiano-Revista de Geografía, n. 2, p. 248-346, 2013.

SILVA, M. A categoria de formação socioespacial e a questão regional: uma aproximação com Gramsci. Observatório Geográfico de América Latina, n. 11, p. 1-7, 2012.

\section{Sobre os autores}

EliasJabbour-eliasjabbour@terra.com.br

Faculdade de Ciências Econômicas, Universidade do Estado do Rio de Janeiro, Rio de Janeiro, RJ, Brasil. ORCID: https://orcid.org/0000-0003-0946-1519.

Alexis Dantas-alexis.dantas@gmail.com

Faculdade de Ciências Econômicas, Universidade do Estado do Rio de Janeiro, Rio de Janeiro, RJ, Brasil. ORCID: https://orcid.org/0000-0002-4742-7197.

\section{Sobre 0 artigo}

Recebido em 16 de junho de 2019. Aprovado em 12 de fevereiro de 2020. 